\title{
Correspondence
}

\section{Coronary spasm in a 59-yr-old woman with byperventilation}

To the Editor:

Severe alkalemia can compromise myocardial perfusion by causing coronary arteriolar constriction, an effect that is more pronounced in respiratory than in metabolic alkalosis. Alkalemia reduces the anginal threshold and predisposes to myocardial ischemia. ${ }^{1}$ We describe a case of acute coronary syndrome provoked by severe respiratory alkalosis.

A 59-yr-old schizophrenic woman was admitted to our intensive care unit (ICU) because of symptomatic acute hyponatremia after massive oral intake of water. Initial arterial blood gas determination showed $\mathrm{pH}$, 7.69; $\mathrm{PaCO}_{2}, 21 \mathrm{mmHg} ; \mathrm{PaO}_{2}, 73 \mathrm{mmHg}$ on room air; $\mathrm{HCO}_{3}, 25 \mathrm{mmol} \cdot \mathrm{L}^{-1}$. The initial electrocardiogram showed sinus rhythm and marked ST-segment elevation in leads V2-V4 and concurrent ST-segment depression in leads II, III, aVF (Figure). The patient did not complain of chest pain, discomfort, or dyspnea but breathed deeply at a rate of 24 breaths. $\mathrm{min}^{-1}$. On admission, troponin I levels were $0.13 \mathrm{ng} \cdot \mathrm{mL}^{-1}$ and peaked at $3.08 \mathrm{ng} \cdot \mathrm{mL}^{-1}$ nine hours later (normal value $<0.1 \mathrm{ng} \cdot \mathrm{mL}^{-1}$ ). ST-segment elevation subsided on the subsequent electrocardiogram obtained four hours after admission, ruling out the initial diagnosis of acute myocardial infarction. Concomitantly, arterial blood gases showed the complete resolution of alkalemia $\left(\mathrm{pH}, 7.42 ; \mathrm{PaO}_{2}, 96 \mathrm{mmHg} ; \mathrm{PaCO}_{2}, 25.3\right.$ $\left.\mathrm{mmHg} ; \mathrm{HCO}_{3}, 16.2 \mathrm{mmol} \cdot \mathrm{L}^{-1}\right)$. The suspicion of acute coronary syndrome was treated with low-molecular-weight heparin, aspirin, clopidogrel and diltiazem. Cardiac catheterization performed $36 \mathrm{hr}$ after ICU-admission revealed stenoses of 50 to $70 \%$ in the left anterior descending and circumflex coronary arteries, and stenosis of 70 to $90 \%$ in the right coronary artery, with thrombolysis in myocardial infarction grade III blood flow. A final diagnosis of hyperventilation-induced transient coronary-artery spasm with underlying chronic ischemic cardiopathy was made.

Severe hyperventilation and alkalemia can provoke chest pain and ST-segment elevation, thereby mimicking acute myocardial infarction. ${ }^{2}$ Alkalemia-induced coronary spasm is usually considered responsible for this acute coronary syndrome, all the more that cardiologists use hyperventilation to induce coronary arterial spasm during cardiac catheterization in patients with suspected Prinzmetal's angina. ${ }^{3}$ In this patient, ischemic changes were likely favoured by a three-vessel coronary artery disease. Severe hyperventilation can be observed in psychiatric conditions, as in this patient, as well as in patients with central nervous sys-

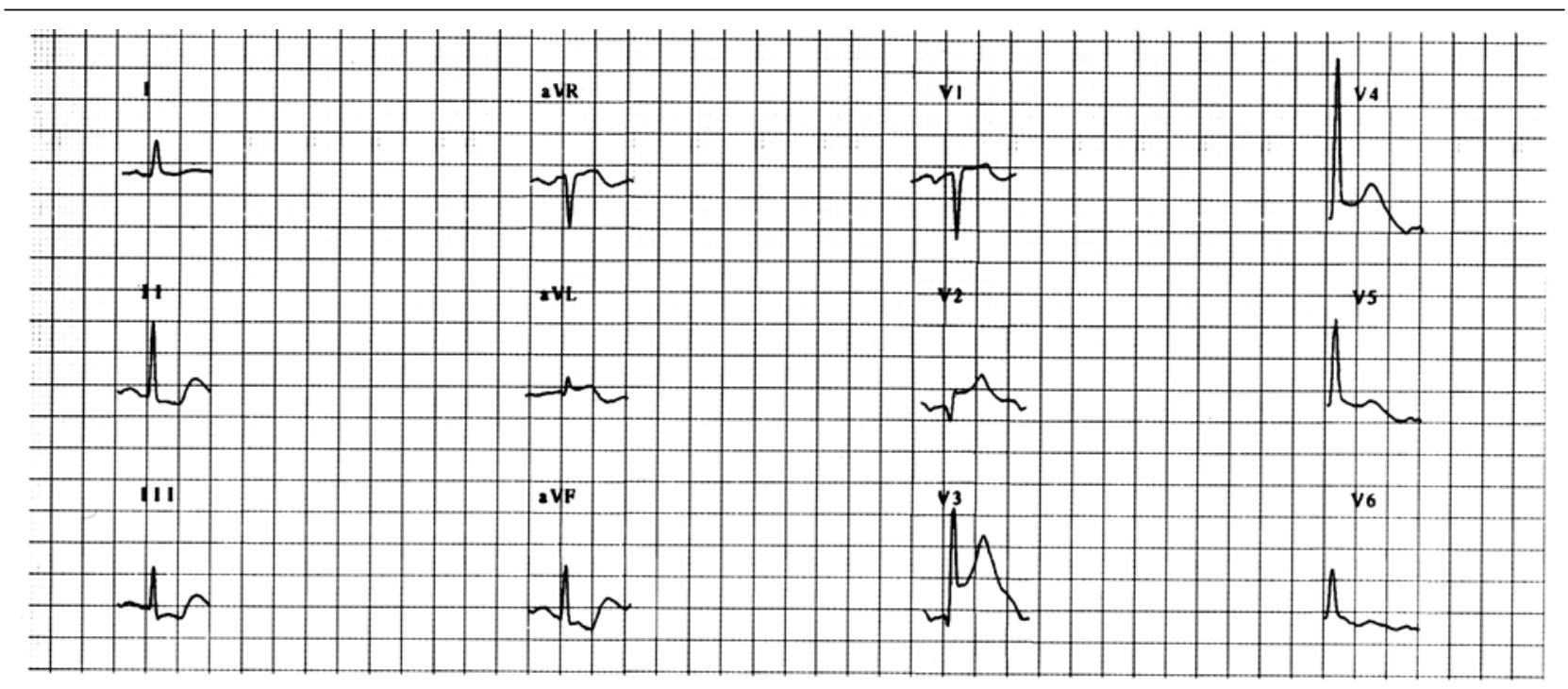

FIGURE Electrocardiogram on admission, reflecting ST-segment elevation in leads V2, V3, V4; and ST-segment depression in leads II, III, aVF. 
tem lesions, or with inappropriate ventilator setting in the ICU or the operating room. ${ }^{1}$ Although prolonged hyperventilation-induced coronary spasm can lead to myocardial infarction even in the absence of underlying coronary disease, ${ }^{4}$ resolution of vasospasm usually occurs rapidly after correction of alkalemia. Calciumantagonists might prove effective in cases of prolonged spasm. ${ }^{5}$

Pascal Fangio MD

Bernard De Jonghe MD

Jean-Claude Lachérade MD

Jean-Pierre Terville MD

Hervé Outin MD

Poissy, France

There was no financial support for this study.

\section{References}

1 Adrogue HJ, Madias NE. Management of life-threatening acid-base disorders. Second of two parts. N Engl J Med 1998; 338: 107-11.

2 Heckerling PS, Hanashiro PK. ST segment elevation in hyperventilation syndrome (Letter). Ann Emerg Med 1985; 14: 1122-3.

3 Chen HS, Pinto DS. Images in clinical medicine. Prinzmetal's angina. N Engl J Med 2003; 349: el.

4 Chelmowski MK, Keelan MH Jr. Hyperventilation and myocardial infarction. Chest 1988; 93: 1095-6.

5 Abernethy DR, Schwartz JB. Calcium-antagonist drugs. N Engl J Med 1999; 341: 1447-57.

\section{Ropivacaine plasma concentrations are similar during continuous lumbar plexus blockade using two techniques: pharma- cokinetics or pharmacodynamics?}

\section{To the Editor:}

We read with interest the recent article published by

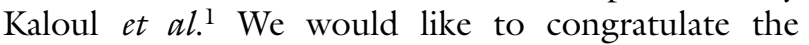
authors for having performed this study looking more closely for the pharmacokinetics of a perineural continuous infusion of ropivacaine. However, we disagree with their final conclusion stating that a continuous infusion of ropivacaine $0.2 \%$ at $12 \mathrm{~mL} \cdot \mathrm{hr}^{-1}$ results in a local anesthetic accumulation and may result in a dangerous blood concentration if maintained at that rate for $48 \mathrm{hr}$. The results of their study do not allow the authors to state that, since the free concentration of ropivacaine, responsible for the pharmacodynamic effects, has not been measured. In a quite similar con- dition it has been shown that the plasma concentration of unbound ropivacaine and unbound 2.6-pipecoloxylidide (the major active metabolite of ropivacaine) added together, does not increase and remains well below threshold levels for systemic toxicity after a continuous infusion of ropivacaine of either 6 or $9 \mathrm{~mL} \cdot \mathrm{hr}^{-1}$ after $48 \mathrm{hr}^{2}$ Surgery is responsible for the release of $\alpha_{1}$-acid glycoprotein which is buffering the free fraction of ropivacaine preventing any dangerous increase in blood concentration. The increase in the total ropivacaine blood concentration observed in both studies is explained by an infusion rate greater than the liver metabolism. ${ }^{3}$ Under these conditions ${ }^{1,2}$ the danger of systemic toxicity is most likely after the initial bolus, not after a continuous infusion as long as the liver continues to release $\alpha_{1}$-acid glycoprotein.

Stephan Blumenthal MD

Georgios Ekatodramis MD

Alain Borgeat MD

Zurich, Switzerland

\section{References}

1 Kaloul I, Guay J, Côté C, Halwagi A, Varin F. Ropivacaine plasma concentrations are similar during continuous lumbar plexus blockade using the anterior three-in-one and the posterior psoas compartment techniques. Can J Anesth 2004; 51: 52-6.

2 Ekatodramis G, Borgeat A, Huledal G, Jeppsson L, Westman L, Sjövall J. Continuous interscalene analgesia with ropivacaine $2 \mathrm{mg} / \mathrm{ml}$ after major shoulder surgery. Anesthesiology 2003; 98: 143-50.

3 Erichsen CJ, Sjövall J, Keblet H, Hedlund C, Arvidsson $T$. Pharmacokinetics and analgesic effect of ropivacaine during continuous epidural infusion for postoperative pain relief. Anesthesiology 1996; 84: 834-42.

REPLY:

Dr. Blumenthal and colleagues disagree that at 12 $m L \cdot h r^{-1}$ ropivacaine accumulates and may result in potentially toxic blood concentrations. As one can see from the figure, steady state was never achieved since the highest blood concentrations were obtained on the last samples. When blood concentrations are increasing during a fixed infusion rate it is because the amount of drug administered is higher than the patient's total elimination. So, yes, our patients were accumulating the drug.

After a major surgery, $\alpha_{1}$-glycoprotein increases as part of the inflammatory response to the surgical stress. It does not mean however that toxic concentrations of local anesthetics (free drug) will never be achieved. Patients with systemic signs of toxicity (pre-seizure) have been seen with infusion for continuous peripheral nerve 